\title{
Knowledge and Attitudes of the Dentists Regarding Oral Cancer in Ankara, Turkey
}

\section{(1) Ömer EKici}

Department of Oral and Maxillofacial Surgery, Faculty of Dentistry, Afyonkarahisar Health Sciences University, Afyonkarahisar-Turkey

\begin{abstract}
OBJECTIVE
Oral cancer is one of the most common cancers in the human body and is a global health concern. This study aims to assess the knowledge and attitudes regarding oral cancer of dentists working in Turkey.

\section{METHODS}

Across-sectional study was carried out in 2019 in Ankara, Turkey. A questionnaire was designed that consisted of dentists' demographic characteristics, knowledge, attitudes, and practices about oral cancer. The questionnaire was distributed to the dentists working at the public oral and dental health care centres in Ankara, Turkey. In the present study, 350 dentists participated.

\section{RESULTS}

Valid questionnaires were attained from 294 dentists. The findings showed that most of the participants were aware of the main risk factors most commonly linked to oral cancer. Only half or fewer of the participants knew the most prevalent type of oral cancer (55.8\%) or the most prevalent oral pre-malignant lesion (44.2\%). It was found that $70.7 \%$ of dentists examined oral mucosa and $47.3 \%$ examined head and neck lymph nodes. $66.7 \%$ of dentists encountered oral malignant/premalignant lesions in the past and only $10 \%$ had training in oral cancers in the past five years.
\end{abstract}

\section{CONCLUSION}

This study highlights a deficit in knowledge among dentists and the need for training activities concerning the early diagnosis of oral cancer in Turkey. Increasing the dentists' knowledge relating to oral cancer examinations is expected to enhance the detection of the number of oral cancers at an earlier stage.

Keywords: Attitude; dentists; knowledge; oral cancer; oral pre-malignant lesion.

Copyright $\odot$ 2020, Turkish Society for Radiation Oncology

\section{Introduction}

Oral cavity and oropharyngeal cancers are the seventh most common cancers and iconcerning mortality, the ninth most lethal in the world.[1] Annually, the forecast number of new cases of oral cancer surpass 300.000 cases[2] and this disease accounts for about 130.000 global deaths per year.[3] Oral cancer is a pub- lic health concern, and it is more prevalent in developing countries than in developed countries.[4] With the exception of skin and thyroid cancers, oral cavity cancer is the second-most prevalent disease in Turkey head and neck cancers, after larynx carcinoma.[5] According to the latest data from GLOBOCAN, 1,910 new oral cancer cases were diagnosed and 792 deaths occurred in Turkey in 2012.[6] It was stated that the 
tongue is the most prevalent oral cancer area in the oral cavity in Turkey.[7] In the literature, however, there is scant research on oral cancer in Turkey.

Tobacco use, chewing, use of snuff, smoking and drinking alcohol are the main risk factors related to oral cancer.[8,9] Human papillomavirus(HPV16 and 18 infections), immune defects, nutrition and diet, and socioeconomic background are other risk factors. [10-12] Almost 95\% of oral cancers occur in people over the age of 40.[13] Although oral cancer may occur in all locations of the oral cavity, it primarily affects the language and mouth floor. Oral cancer occurs predominantly in the form of squamous cell carcinoma. Early diagnosis of suspected oral lesions, including erythroplakia and leucoplakia, is the most effective means of decreasing oral cancer mortality and morbidity.[14] The probability of survival is remarkably higher if diagnosis in an advanced phase is diagnosed early.[15]

The World Health Organization (WHO) Global Oral Health Programs contains two approaches for preventing oral cancer: reduction of exposure to risk factors and early detection through screening.[9] In 2007, the WHO's global oral health strategy underlined that oral health practitioners are involved as part of the national cancer management program's early detection, diagnosis, and treatment programs.[16] Dentists and other members of the dental team play a vital role in decreasing the occurrence of oral cancer by early detection of the lesions of high-risk patients' oral cancer. [17] While there are various studies worldwide to determine the understanding and actions of dentists in oral cancer,[18-22] there is no comprehensive study that evaluates the knowledge and attitudes of Turkish dentists regarding oral cancers. This cross-sectional study aims to evaluate knowledge and awareness of oral cancer among dentists in Ankara, Turkey.

\section{Materials and Methods}

This cross-sectional study was approved by the ethics committee of the Faculty of Medicine, Afyonkarahisar Health Sciences University (2019/3-55). Permission was obtained from the Ministry of Health, Ankara Provincial Health Directorate, for this study (May 27, 2019E.7790). In addition, permission and approval were obtained from the administration of seven of the nine oral and dental health centres in Ankara. Two centres were excluded from this study because they did not approve the research, and this study was carried out in seven oral and dental health centres. This study was conducted in accordance with the Helsinki Declaration principles.
A questionnaire was designed consisting of dentists' demographic characteristics, knowledge, attitudes, and practices of oral cancer. Knowledge questions of the survey were formulated to investigate a dentist's awareness of oral cancer epidemiology, risk factors, symptoms, specific sites and general features of oral lesions. The validity and reliability of the questions were confirmed using a pre-test method with a pilot group of 25 dentists. Dentists working in the oral and dental health centres were visited and their consent was obtained for the survey. The questionnaires were applied to 350 dentists working in seven oral and dental health centres. Statistical analyses were performed using Statistical Package for the Social Sciences (SPSS) software (version 22.0, SPSS, Inc., Chicago, IL). Data were expressed by frequencies and percentages.

\section{Results}

Two hundred ninety-four valid questionnaires were attained from participants, a response rate of $84 \%$. The validity criterion was that all the questions in the questionnaire were read and answered. Therefore, surveys in which half or fewer of the questions were completed were considered invalid. The demographic data of the participants are shown in Table 1. Most of the participants in this study were male, aged 35 years or more and married. Approximately three-quarters of the participants had more than ten years of clinical experience.

\begin{tabular}{|c|c|c|}
\hline Demographic data & Number (n) & Percentage (\%) \\
\hline \multicolumn{3}{|l|}{ Age } \\
\hline $25-34$ years old & 67 & 22.8 \\
\hline 35-44 years old & 104 & 35.4 \\
\hline 45-54 years old & 108 & 36.7 \\
\hline 55 years old $\leq$ & 15 & 5.1 \\
\hline \multicolumn{3}{|l|}{ Gender } \\
\hline Male & 117 & 39.8 \\
\hline Female & 177 & 60.2 \\
\hline \multicolumn{3}{|l|}{ Marital status } \\
\hline Married & 104 & 68.4 \\
\hline Single & 48 & 31.6 \\
\hline \multicolumn{3}{|l|}{ Working experience } \\
\hline $1-5$ years & 33 & 11.2 \\
\hline $6-10$ years & 35 & 11.9 \\
\hline $11-15$ years & 69 & 23.5 \\
\hline $15-20$ years & 48 & 16.3 \\
\hline 20 years and more & 109 & 37.1 \\
\hline Total & 294 & 100 \\
\hline
\end{tabular}


Figure 1 shows the number and percentage distribution of the answers given by dentists to the general and epidemiological characteristics of oral cancers. $58.5 \%$ of the dentists correctly answered the statements in the survey: '0ral cavity and oropharyngeal cancers are among the ten most common cancers in the world' and 'Oral cancer has high morbidity and mortality'. However, $75.9 \%$ of the dentists did not know that the five-year survival rate in oral cancer was below $70 \%$. More than half the dentists erroneously thought that oral cancers are always asymptomatic and have a good prognosis. Interestingly, 51\% of dentists did not know that oral cancer is a preventable disease.

Figure 2 illustrates the distribution of correct answers for risk factors of oral cancer. Concerning risk factors, a high percentage of dentists correctly reported the use of tobacco products (93.5\%), oral cancer history (90.1\%), use of alcohol (86.7\%), exposure to ultraviolet rays $(83.7 \%)$, radiotherapy history $(82.3 \%)$ and human papillomavirus (HPV) (76.9\%) as the risk factors for oral cancer. However, they incorrectly responded that obesity (30.6\%), spicy foods (17\%) and hot food and drinks (13.8\%) were risk factors of oral cancer. Only about $52.4 \%$ of dentists were aware that 'old age' plays a major role in the occurrence of oral cancer.

In the study, it was observed that the correct response rate in the answers given to the questions about the clinical features and localisation of oral cancer was quite low. Nearly half of the respondents correctly selected 'squamous cell carcinoma' as the most prevalent form of cancer in the oral cavity (55.8\%) and 'leukoplakia' as the most common premalignant lesion (44.2\%). About $35 \%$ of respondents correctly chose 'tongue' as the most common cancer site, and 27.9\% correctly chose the second most susceptible site as the floor of the mouth for oral cancer. $33.7 \%$ of the participants correctly selected 'the ventral lateral margin' as the most sensitive area of the tongue for oral cancer.

Table 2 illustrates the attitude and behaviour of the dentists regarding oral cancer. It was revealed that $70.7 \%$ of dentists examined the oral mucosa of patients, $47.3 \%$ examined the lymph nodes, and $34.7 \%$ take a biopsy of suspected oral lesions. Only $38.1 \%$ of dentists received training on oral malignant and premalignant lesions before graduation, and $10 \%$ had training on oral cancers in the past five years. Only $29.3 \%$ dentists thought that they had sufficient knowledge about oral cancer detection and prevention information.

\section{Discussion}

Dentists have a major role and duty in the prevention and early detection of oral cancer since it is a disease that is difficult to recognise in its early stages. Understanding and evaluating the awareness, attitudes, and practices of dentists and their efficacy in early detec-

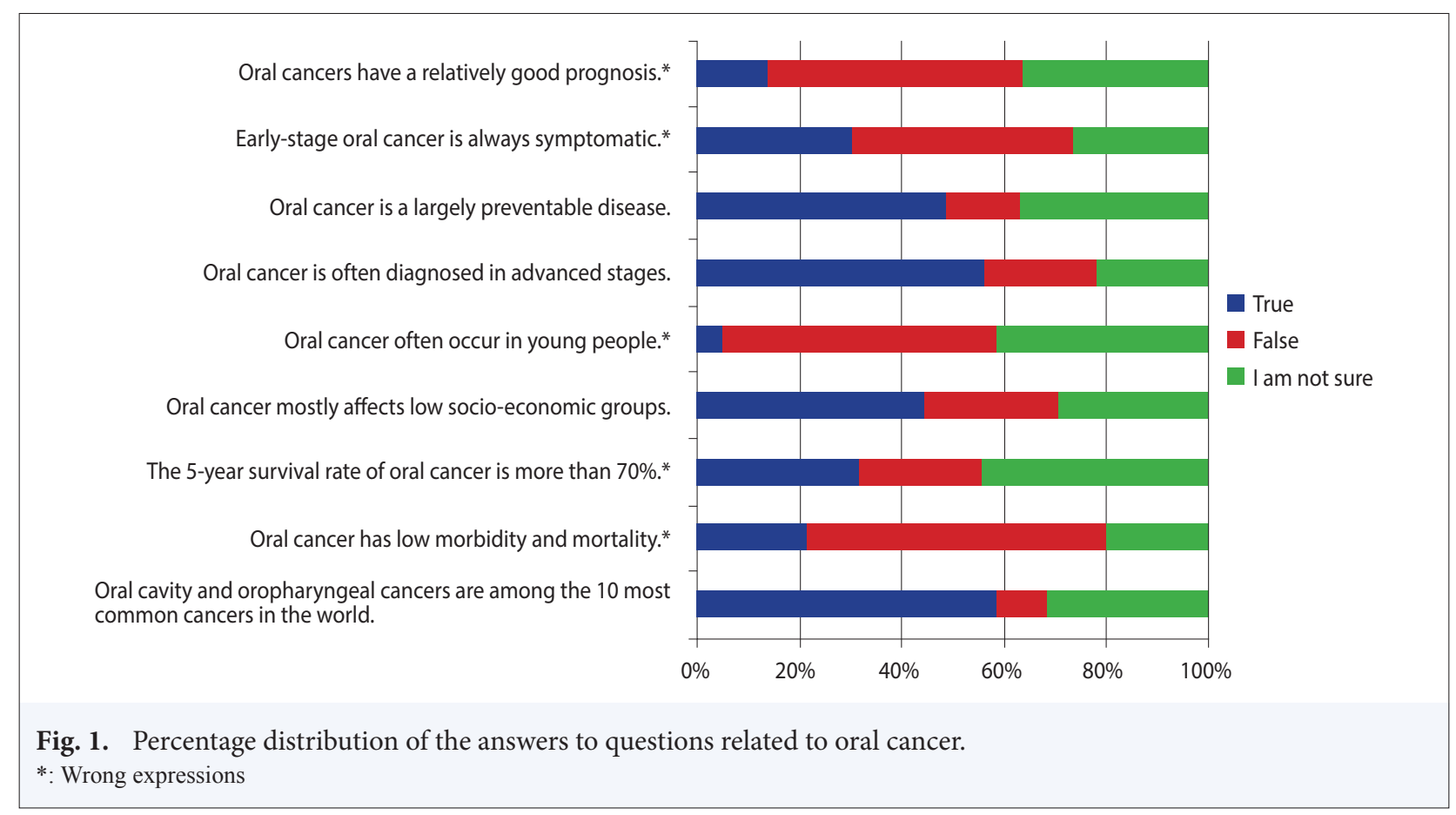


Table 2 Attitudes and practices of the dentists related to oral cancer

\begin{tabular}{|c|c|c|}
\hline Questions & Yes n(\%) & No $n(\%)$ \\
\hline 1. Do you regularly examine the oral mucosa of patients? & $208(70.7 \%)$ & $86(29.3 \%)$ \\
\hline 2. Do you perform lymph node examination in patients? & 139 (47.3\%) & $155(52.7 \%)$ \\
\hline 3. Do you perform a biopsy of suspected oral lesions? & $102(34.7 \%)$ & $192(65.3 \%)$ \\
\hline 4. Do you record patients' habits such as smoking, alcohol or substance abuse? & $77(26.2 \%)$ & $217(73.8 \%)$ \\
\hline 5. Do you advise patients on oral cancer risk factors? & $141(48.0 \%)$ & $153(52.0 \%)$ \\
\hline 6. Do you perform periodic examination, training, and follow-up of high-risk patients? & $100(34.0 \%)$ & $194(66.0 \%)$ \\
\hline 7. Have you encountered any oral malignant/premalignant lesions? & $196(66.7 \%)$ & $98(33.3 \%)$ \\
\hline 8. Do you think you have enough information about the detection and prevention of oral cancer? & $86(29.3 \%)$ & $208(70.7 \%)$ \\
\hline $\begin{array}{l}\text { 9. Have you received adequate pre-graduation training in diagnosing oral } \\
\text { malignant/premalignant lesions? }\end{array}$ & $112(38.1 \%)$ & $182(61.9 \%)$ \\
\hline 10. Did you receive any training in oral cancer in the last five years? & $30(10.2 \%)$ & $264(89.8 \%)$ \\
\hline 11. Would you like more information and training on oral cancer? & $229(77.9 \%)$ & $65(22.1 \%)$ \\
\hline
\end{tabular}

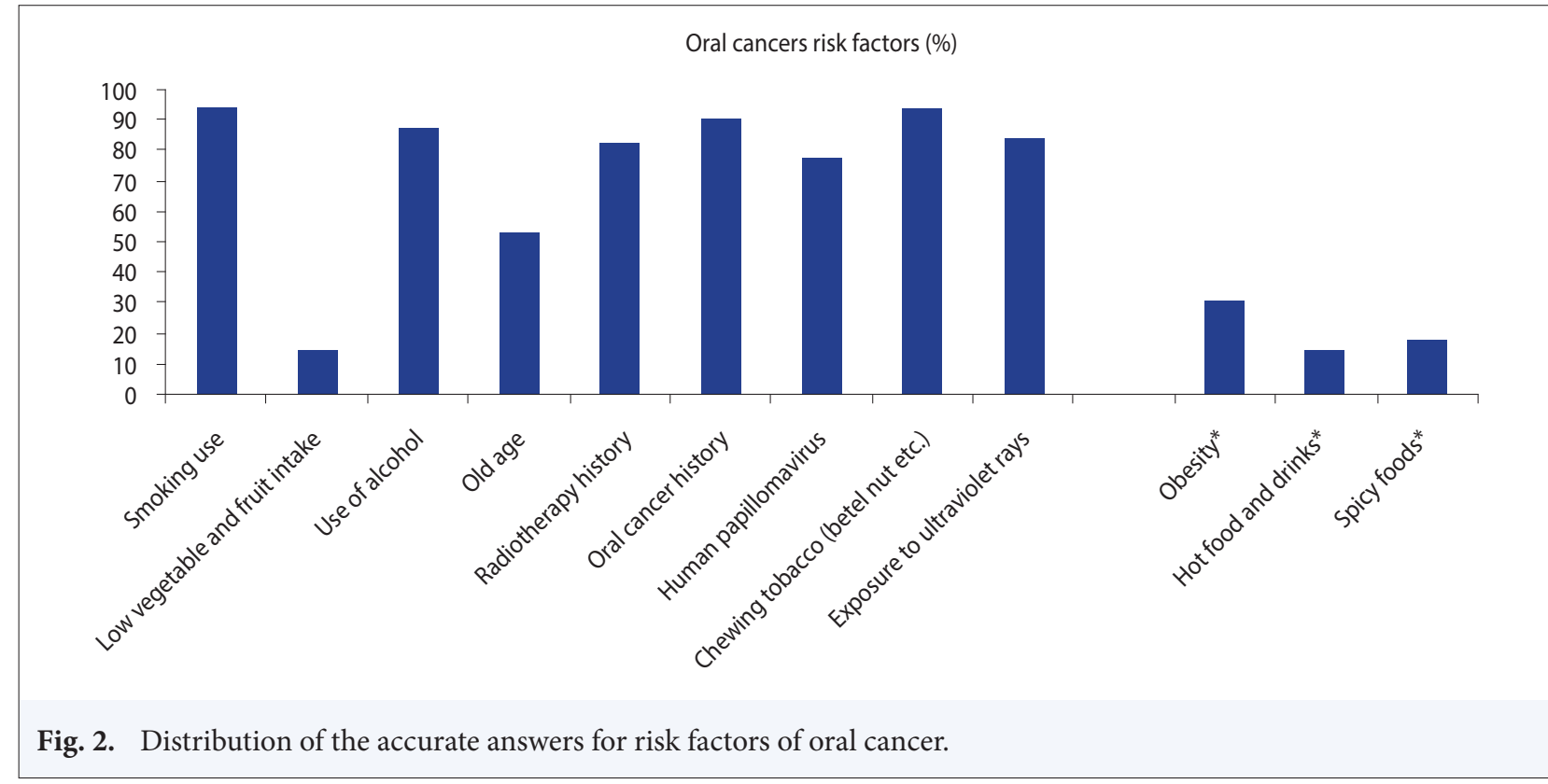

tion are significant in reducing oral cancer mortality and morbidity.[23] Therefore, the knowledge and awareness of dentists regarding oral cancer were evaluated in this report.

Tobacco and alcohol use are the major risk factors for oral cancer. In this study, $93.5 \%$ and $86.7 \%$ of the dentists consider smoking and alcohol use, respectively, as a risk factor for oral cancer. Almost all dentists in the survey conducted in Spain rightly evaluated the use of tobacco $(100 \%)$ and alcohol $(96.4 \%)$ to be the major risk factors. [24] In a survey conducted in Italy, similarly, tobacco $(94.1 \%)$, alcohol (79.2\%), previous oral cancer lesions (89.5\%), and older age (47.9) were considered as the major risk factors.[25] However, in the present study, only about $52.4 \%$ of dentists were aware that age plays a significant role in the development of oral cancer. Alaizari and Al-Maweri [26] similarly observed that older age is only suggested as a possible risk factor for oral cancer by $48 \%$ of Yemen dentists. In this study, only $13.9 \%$ of dentists considered the low intake of vegetables and fruits as a risk factor for oral cancer. It is also seen that there is a deficit of knowledge that low intake of fruit and vegetables is also a risk factor. In this study, obesity (30.6\%), hot foods and beverages $(13.8 \%)$ and spicy foods (17\%) were incorrectly cited as risk factors for oral cancer. As a result, it has been revealed that the knowledge of dentists on oral cancer risk factors is insufficient. 
The most common form of cancer in the oral cavity is squamous cell carcinoma. Although leukoplakia is the prevalent premalignant lesion, most dysplastic changes in erythroplakia lesions are detected, rendering oral cancer examinations a matter of concern. [27] Nearly half of the respondents correctly selected 'squamous cell carcinoma' as the most common type of cancer (55. $8 \%$ ), and $44.2 \%$ of participants correctly selected 'leukoplakia' as the most common premalignant lesion. In the study conducted by Kebapçığlu et al.[28], 64.1\% of Turkish dentists correctly identified erythroplakia and leukoplakia as premalignant lesions and $64.7 \%$ of the dentists regarded squamous cell carcinoma as the most prevalent oral cancer type. In contrast, the study carried out by Lopez et al.[24] indicated that most dentists (90.6\%) identified oral squamous cell carcinoma as the most prevalent form of oral cancer, which is similar to the percentage observed among dentists in Yemen,[26] Kuwait,[29] and North Carolina.[30] Fewer than half of dentists indicated the tongue $(35 \%)$ and floor of the mouth $(27.9 \%)$ as the most frequent sites of oral cancer in the present study. In a similar study conducted in Turkey, $37 \%$ of the dentists indicated the tongue and floor of the mouth as the most prevalent location of oral cancer.[28] This is of concern because Turkish dentists demonstrate that they do not have sufficient knowledge of oral lesions and malignant changes.

Oral cancers can be diagnosed early because they primarily arise in places that can be seen and easily accessed through a non-invasive examination. Thus, dentists should thoroughly examine the patient.[31] In the study, $77.7 \%$ of dentists stated that they examined the oral mucosa completely, while $47.3 \%$ stated that they performed head-neck lymph node examination. Khattab et al.[32] reported that only $26.5 \%$ of dentists in Egypt perform routine lymph-node palpation during dental visits and that they did so only when there were patient complaints. In this study, dentists claimed that they record patients' habits such as smoking, alcohol or substance abuse (26.2\%) and advise patients on risk factors for oral cancer (48\%). In another study, 38.2\% of the dentists in Turkey indicated that their patients were informed about alcohol and tobacco use is a risk factor for oral cancer.[28] By comparison, in a study conducted in India, the rate of dentists who informed the patient about oral cancer risk factors was reported as 68\%.[33] Actually, a patient's visit to the dentist is an opportunity for them to receive a comprehensive oral examination and oral health education. Unfortunately, these deficiencies in information and practice prevent early detection of oral cancers. This study identified gaps in knowledge among dentists practicing in the government sector of Turkey.

While early detection is a key factor in improving the survival rate, most oral malignant tumors are not diagnosed until they are in advanced stages. Dentists play a vital role in the early detection and prevention of oral cancer. Thus, they should conduct cancer screenings at each patient's visit and pay particular attention to patients at high risk. As the gold standard for the early diagnosis of oral cancer is the visual analysis of any oral epithelial changes, this examination should be a routine procedure at the oral and dental care centres in Turkey. Dentists should receive special training on smoking and alcohol cessation, as dental clinics are ideal places for smoking cessation interventions. They should perform a biopsy of suspicious lesions that do not heal within three weeks or whose cause is unknown. In addition, dentists should update their knowledge of oral cancers by attending various training after graduation. Thus, continuous education and training programs should be organised on the symptoms of oral cancers, risk factors, treatment methods and the importance of early diagnosis under the leadership of the Ministry of Health and the Turkish Dental Association.

\section{Limitations of the Study}

One limitation of this study is that private dentists are not included. In addition, the dentists have been selected from only one city, which may limit the generalisability of findings, although the dental education curriculum is very similar across the country this study was conducted.

\section{Conclusion}

This study stresses the need for dentist training on risk factors and early diagnosis of oral cancer in Turkey. Early detection of suspected oral premalignant lesions provides the greatest potential to gain control over oral cancer mortality and morbidity. Thus, oral cancer screening should also be a standard practice at public oral and dental health care facilities for high-risk patients. An additional focus should also be placed on oral cancer education in Turkish dental schools.

Acknowledgments: I thank the Ministry of Health, Ankara Provincial Health Directorate and administration of public oral and dental health centers in Ankara for permission of the survey. Also, I thank all the dentists who participated in the survey in this study. 
Peer-review: Externally peer-reviewed.

Conflict of Interest: None of the authors have any conflicts of interest or financial ties to disclose.

Ethics Committee Approval: This study was approved by the Human Research Ethics committee of the Faculty of Medicine, Afyonkarahisar Health Sciences University (2019/3-55). This study was carried out in accordance with the Helsinki Declaration principles. Informed consent was obtained from all participants included in this study.

Financial Support: This research did not receive any specific grant from funding agencies in the public, commercial, or not-for-profit sectors.

Authorship contributions: Concept - Ö.E.; Design - Ö.E.; Supervision - Ö.E.; Funding - Ö.E.; Materials - Ö.E.; Data collection and/or processing - Ö.E.; Data analysis and/or interpretation - Ö.E.; Literature search - Ö.E.; Writing - Ö.E.; Critical review - Ö.E.

\section{References}

1. Stewart BW, Wild CP. World cancer report 2014. World Health Organ. 1-2. Available at: http://www. videnza.org/wp-content/uploads/World-Cancer-Report-2014.pdf Accessed Dec 25, 2019.

2. Al-Jaber A, Al-Nasser L, El-Metwally A. Epidemiology of oral cancer in Arab countries. Saudi Med J 2016;37(3):249-55.

3. Petti S, Scully C. Oral cancer knowledge and awareness: primary and secondary effects of an information leaflet. Oral Oncol 2007;43(4):408-15.

4. Kujan O, Farah CS, Johnson NW. Oral and oropharyngeal cancer in the Middle East and North Africa. Transl Res Oral Oncol. 2017;2:1-9.

5. Düzlü M, Karamert R, Bakkal FK, Cevizci R, Tutar H, Zorlu ME, et al. The demographics and histopathological features of oral cavity cancers in Turkey. Turk J Med Sci 2016;46(6):1672-6.

6. Cancer Tomorrow. Available at: http://gco.iarc.fr/tomorrow/home Accessed Dec 25, 2019.

7. Uğurluer G, Ozyurt SC, Aksaray F, Aslan N, Habiboğlu R, Tümöz M. Prognostic factors and survival rates in oral cavity cancers. Kulak Burun Bogaz Ihtis Derg. 2006;16(2):64-71.

8. Rodriguez T, Altieri A, Chatenoud L, Gallus S, Bosetti C, Negri E, et al. Risk factors for oral and pharyngeal cancer in young adults. Oral Oncol 2004;40(2):207-13.

9. Petersen PE. Oral cancer prevention and control--the approach of the World Health Organization. Oral Oncol 2009;45(4-5):454-60.

10. Meurman JH. Infectious and dietary risk factors of oral cancer. Oral Oncol 2010;46(6):411-3.
11. Llewellyn CD, Johnson NW, Warnakulasuriya KA. Risk factors for squamous cell carcinoma of the oral cavity in young people--a comprehensive literature review. Oral Oncol 2001;37(5):401-18.

12. Freedman ND, Park Y, Subar AF, Hollenbeck AR, Leitzmann MF, Schatzkin A, et al. Fruit and vegetable intake and head and neck cancer risk in a large United States prospective cohort study. Int J Cancer 2008;122(10):2330-6.

13. Silverman S Jr, Kerr AR, Epstein JB. Oral and pharyngeal cancer control and early detection. J Cancer Educ 2010;25(3):279-81.

14. Silverman S Jr. Controlling oral and pharyngeal cancer. Can dental professionals make a difference? J Am Dent Assoc 2005;136(5):576-8.

15. Sankaranarayanan R, Ramadas K, Thomas G, Muwonge R, Thara S, Mathew B, et al. Effect of screening on oral cancer mortality in Kerala, India: a cluster-randomised controlled trial. Lancet 2005;365(9475):1927-33.

16. Petersen PE. World Health Organization global policy for improvement of oral health--World Health Assembly 2007. Int Dent J 2008;58(3):115-21.

17. Kujan O, Duxbury AJ, Glenny AM, Thakker NS, Sloan P. Opinions and attitudes of the UK's GDPs and specialists in oral surgery, oral medicine and surgical dentistry on oral cancer screening. Oral Dis 2006;12(2):194-9.

18. Hertrampf K, Wiltfang J, Koller M, Klosa K, Wenz HJ. Dentists' perspectives on oral cancer: a survey in Northern Germany and a comparison with international data. Eur J Cancer Prev 2010;19(2):144-52.

19. Leonel ACLDS, Soares CBRB, Lisboa de Castro JF, Bonan PRF, Ramos-Perez FMM, Perez DEDC. Knowledge and Attitudes of Primary Health Care Dentists Regarding Oral Cancer in Brazil. Acta Stomatol Croat 2019;53(1):55-63.

20. Navabi N, Hashemipour MA, Roughani A. Validation of a Persian Short-Form Version of a Standardised Questionnaire Assessing Oral Cancer Knowledge, Practice and Attitudes Among Dentists. Sultan Qaboos Univ Med J 2017;17(1):80-7.

21. Akbari N, Raeesi V, Khazaei T, Ramezanzadeh K, Ebrahimipour S. Evaluation of General Dentists' and Dental Specialists' Knowledge about Oral Cancer in South Khorasan-Iran 2014. Asian Pac J Cancer Prev 2015;16(16):6987-90.

22. Razavi SM, Zolfaghari B, Foroohandeh M, Doost ME, Tahani B. Dentists' knowledge, attitude, and practice regarding oral cancer in Iran. J Cancer Educ 2013;28(2):335-41.

23. Horowitz AM, Drury TF, Goodman HS, Yellowitz JA. Oral pharyngeal cancer prevention and early detection. Dentists' opinions and practices. J Am Dent Assoc 2000;131(4):453-62. 
24. López-Jornet P, Camacho-Alonso F, Molina-Miñano F. Knowledge and attitudes about oral cancer among dentists in Spain. J Eval Clin Pract 2010;16(1):129-33.

25. Colella G, Gaeta GM, Moscariello A, Angelillo IF. Oral cancer and dentists: knowledge, attitudes, and practices in Italy. Oral Oncol 2008;44(4):393-9.

26. Alaizari NA, Al-Maweri SA. Oral cancer: knowledge, practices and opinions of dentists in yemen. Asian Pac J Cancer Prev 2014;15(14):5627-31.

27. Epstein JB, Gorsky M, Cabay RJ, Day T, Gonsalves W. Screening for and diagnosis of oral premalignant lesions and oropharyngeal squamous cell carcinoma: role of primary care physicians. Can Fam Physician 2008;54(6):870-5.

28. Kebabcioğlu Ö, Pekiner FN. Assessing Oral Cancer Awareness Among Dentists. J Cancer Educ 2018;33(5):1020-6.

29. Joseph BK, Sundaram DB, Sharma P. Oral cancer awareness among dentists in Kuwait. Med Princ Pract. 2012;21(2):164-70.

30. Patton LL, Elter JR, Southerland JH, Strauss RP. Knowledge of oral cancer risk factors and diagnostic concepts among North Carolina dentists. Implications for diagnosis and referral. J Am Dent Assoc 2005;136(5):602-10; quiz 682.

31. Brocklehurst P, Kujan O, O’Malley LA, Ogden G, Shepherd S, Glenny AM. Screening programmes for the early detection and prevention of oral cancer. Cochrane Database Syst Rev 2013;(11):CD004150.

32. Khattab NMA, Elheeny AAH, Tony GA. Oral-cancer knowledge, practice, and attitude assessment of dentists in Upper Egypt: A cross-sectional study. Clin Exp Dent Res. 2019;5(2):121-7.

33. Vijay Kumar KV, Suresan V. Knowledge, attitude and screening practices of general dentists concerning oral cancer in Bangalore city. Indian J Cancer 2012;49(1):33-8. 